\title{
Correlation between Serum Creatine Phosphokinase and Severity of Acute Organophosphorus Poisoning: A Prospective Clinical Study (2012-2013)
}

\author{
Nermeen A. M. Hassan, M.D.*1 and Abdelmonem G. Madboly, M.D. ${ }^{2}$ \\ ${ }^{1}$ Forensic Medicine \& Clinical Toxicology Department, Benha University, Egypt \\ ${ }^{2}$ Forensic Medicine \& Clinical Toxicology Department, Benha University, \\ Consultant of Clinical Toxicology, Benha Poisoning Control Unit, Benha University Hospitals, Egypt
}

\begin{abstract}
Organophosphorus (OP) poisoning is an important global health problem especially in developing countries like Egypt. . Estimation of erythrocyte cholinesterase (EChE) and butyrylcholinesterase (BChE) as an evidence of $O P$ poisoning is costly, not regularly performed and shows wide inter-individual variability. Therefore, this study was designed to assess if serum creatine phosphokinase (CPK) can be used as a cheaper and easily available biomarker alternative of cholinesterase to stratify OP poisoning severity. All symptomatic patients within 6 hours of exposure to $O P$ and without prior treatment who were admitted to Benha poisoning control unit (BPCU), Benha university hospitals, Egypt, during the period from $1^{\text {st }}$ October 2012 to $31^{\text {st }}$ March 2013 were enrolled in this study. The clinical severity of patients was categorized according to Peradeniya organophosphorus poisoning (POP) scale. The Glasgow coma scale (GCS), total dose of atropine "mg" and obidoxime " $g$ " until final clinical outcome were calculated. BChE, $p H$ and serum CPK levels were estimated following admission. ANOVA (F) test, Paired " $t$ " test and Spearman's correlation coefficient (rho) were used as tests of significance. The total number was 60 patients; $51.7 \%$ were mild, $33.3 \%$ were moderate and $15 \%$ were severe. There was a highly significant correlation between initial serum CPK levels and severity of acute $O P$ poisoning. This study recommends $C P K$ as an alternative biomarker for acute OP poisoning.
\end{abstract}

Keywords: Creatine phosphokinase, Organophosphorus, Butyrylcholinesterase, Peradeniya organophosphorus

Poisoning scale

\section{Introduction}

The generic term "organophosphorus" or "OP" is used for a wide variety of chemicals that are derived from phosphoric, phosphonic and phosphinic acids [1].OP compounds have been used as pesticides and developed as chemical warfare nerve agents. They can be efficiently absorbed by inhalation, ingestion and skin penetration [2]

OP compounds are prevalent worldwide in the agriculture as well as in the household gardens. Their easy availability combined with their sale over the counter has resulted in a gradual increase in poisoning with these agents [3]. Poisoning with OP compounds is important global health problem, and is possibly the most common acute poisoning in the developing countries [4,5]. More than 100 different OP compounds have been synthesized. The most well-known are malathion, parathion, fenthion, diazinon, dimethoate, chlorpyrifos, paraoxon and soman [6].

OP insecticides are irreversible inhibitors of carboxylic ester hydrolases, including acetylcholinesterase (AChE), erythrocyte cholinesterase (EChE), plasma or butyrylcholinesterase (BChE) and other nonspecific proteases. The primary toxicity from these compounds is derived from excessive stimulation of muscarinic and nicotinic cholinergic receptors by the accumulated acetylcholine in the central and autonomic nervous systems as well as at skeletal neuromuscular junctions [7].

Furthermore, OP insecticides increase reactive oxygen species level which results in oxidative stress that contributes to cell membrane lipid peroxidation, DNA damage and cell death $[8,9]$.

Medical students are often taught to associate OP poisoning with the acronym SLUDGE - salivation, lacrimation, urination, defecation, gastrointestinal distress, and emesis. Unfortunately these are all fairly generic symptoms that would not prompt an emergency caregiver to consider OP poisoning unless the medical history suggested $\mathrm{OP}$ exposure $[10,11]$.

Laboratory evidence of OP poisoning is usually confirmed by measuring the decreases in the $\mathrm{BChE}$ and EChE activities. However, because of wide inter-individual variability, significant depression of the enzyme cholinesterase activity may occur but still fall within the "normal" range [12]. Also, estimation of either serum $\mathrm{EChE}$ or BChE levels is costly and not regularly performed in most laboratories [13]. 
There are emerging options for new cheaper and/or easily quantifiable biochemical markers in relation to OP poisoning like creatine phosphokinase $(\mathrm{CPK})$, lactate dehydrogenase $(\mathrm{LDH})$ and serum immunoglobulins (IgG, IgA). But immunoglobulin assays, apart from being costly and difficult to perform in most laboratories, are often unreliable [14].

Several animal model studies proposed that serum level of CPK is often found to be elevated in OP poisoning, and it may be used as a biomarker [15].

Therefore, this study was conducted to assess the correlation between serum CPK levels and the severity of acute OP poisoning, to see if serum CPK level can be used as an alternative of BChE level to stratify OP poisoning severity.

\section{PATIENTS}

\section{Patients And Methods}

This is a prospective clinical study that was carried out on patients with acute organophosphorus (OP) poisoning of both sexes and of different age groups, who were admitted to Benha poisoning control unit (BPCU), Benha university hospitals, Egypt, during the period from $1^{\text {st }}$ October 2012 to $31^{\text {st }}$ March 2013.

Only symptomatic patients within 6 hours of exposure to OP and without prior treatment were included in the study after taking their informed consent. The study was approved by Institutional ethical committee.

Patients with history of any diseases or conditions that may alter results of laboratory investigations (CPK level) like, myopathy, chronic renal disease, epilepsy, known psychiatric illness, recent intramuscular injections, myocardial infarction, myocarditis, trauma, malignancy or overwhelming sepsis....etc., were excluded from the study.

Diagnosis of acute OP poisoning was based on; a) history of intake or exposure to OP, combined with complaint of the characteristic symptoms of cholinergic toxidrome, b) physical examination to detect characteristic signs of cholinergic toxidrome, c) laboratory assessment of butyrylcholinesterase (BChE) level. Clinical severity was categorized according to Peradeniya organophosphorus poisoning (POP) scale, as illustrated in Table (1) [16].

\section{Table 1}

Peradeniya Organophosphorus Poisoning (POP) Scale, (0-3, Mild Poisoning; 4-7, Moderate Poisoning; 8-11, Severe Poisoning) [16].

\begin{tabular}{|c|c|c|}
\hline Parameter & Findings & Scale \\
\hline \multirow{3}{*}{ Pupil size } & $\geq 2 \mathrm{~mm}$ & 0 \\
\hline & $<2 \mathrm{~mm}$ & 1 \\
\hline & Pinpoint & 2 \\
\hline \multirow{3}{*}{ Respiratory rate } & $<20 /$ minute & 0 \\
\hline & $\geq 20 /$ minute & $T$ \\
\hline & $\geq 20 /$ minute with cyanosis & 2 \\
\hline \multirow{3}{*}{ Heart rate } & $>60 /$ minute & 0 \\
\hline & $41-60 /$ minute & 1 \\
\hline & $<40 /$ minute & 2 \\
\hline \multirow{3}{*}{ Fasciculations } & None & 0 \\
\hline & Present, \pm generalized \pm continues & 1 \\
\hline & Both generalized \& continuous & 2 \\
\hline \multirow[t]{3}{*}{ Consciousness level } & Conscious \& oriented & 0 \\
\hline & Impaired verbal response & 1 \\
\hline & No verbal response & 2 \\
\hline \multirow{2}{*}{ Seizures } & Absent & 0 \\
\hline & Present & 1 \\
\hline
\end{tabular}

Patients were treated with intravenous bolus of atropine (1-5 mg for adults, and $0.05 \mathrm{mg} / \mathrm{kg}$ for children), repeated doses of 1-2 mg infusion every 5-10 minutes, until dryness of chest secretions or atropinization occur; obidoxime "toxogonin" (initial dose in adults: $250 \mathrm{mg}$, in children $4-8 \mathrm{mg} / \mathrm{kg}$ ), then continuous infusion at a dose of $750 \mathrm{mg} / 24$ hours in adult and in children at a dose of $10 \mathrm{mg} / \mathrm{kg}$ daily. This was done after initial stabilization of patient and concomitant with proper decontamination. Intramuscular injections were avoided during treatment.

\section{METHODS}

A valid consent was taken from each patient for obtaining medical history, clinical examination and for the permission to take blood samples for laboratory investigations. 
Demographic data including the following features were studied (age, gender, residence, occupation, OP compound involved, rout of exposure, manner of exposure).

\section{All patients were clinically studied according to the followings:}

- Characteristic symptoms and signs of cholinergic toxidrome.

- The Glasgow coma scale (GCS).

- $\quad$ Clinical severity according to POP scale.

- Treatment measures (total dose of atropine in "mg" and obidoxime in "g" until final clinical outcome).

Biochemical analysis of $\mathrm{BChE}, \mathrm{pH}$, and serum $\mathrm{CPK}$ were estimated following admission.

Samples were collected by a single prick after initial resuscitation and stabilization of patient, from a peripheral vein without tying any tourniquet, nor adding any anticoagulants.

$\mathrm{BChE}$ levels were estimated spectrophotometrically using the commercial kit of cholinesterase SGM Italy, with Spinlab (Spinreact Company, Spain) by the kinetic butyrylthiocholine method. Reference value [4850 -12000 IU/l] [17].

- $\quad$ CPK levels were estimated spectrophotometrically using the commercial kit of creatinkinase SGM Italy, with Spinlab (Spinreact Company, Spain) by the UV kinetic optimized method. Reference values [24 -195 $\mathrm{IU} / 1$ in male and $24-170 \mathrm{IU} / 1$ in females] [18].

Serum CPK was re-evaluated just before discharging patients after completing the treatment course or after completion of 1 week, whichever was earlier.

- $\quad$ The blood $\mathrm{pH}$ was measured spectrophotometrically by EliTech IRMA truPoint blood gas analyzer (UK). Reference value (7.35-7.45) at $37^{\circ} \mathrm{C}$ [19].

All results obtained from patients were registered in special sheets of study, which were confidential.

\section{STATISTICAL ANALYSIS OF THE DATA}

The collected data were organized, tabulated and analyzed using SPSS version 16 software (SpssInc, Chicago, ILL Company). Categorical data were presented as number and percentages while quantitative data were expressed as mean and standard deviation. ANOVA (F) test, Paired " $\mathrm{t}$ " test and Spearman's correlation coefficient (rho) were used as tests of significance. ROC curve was used to compare the accuracy of initial CPK levels and BChE levels in diagnosis of acute OP poisoning. The accepted level of significance in this work was stated at 0.05 , ( $\mathrm{P}<0.05$ was considered significant) [20].

\section{DEMOGRAPHIC RESULTS:}

\section{Results}

Out of 60 patients enrolled in the study, $29(48.3 \%)$ were males and $31(51.7 \%)$ were females. They were aged from 2 to 53 years. Thirty two (53.3\%) came from rural areas, whereas $28(46.7 \%)$ from urban areas. Regarding occupation, $22(36.7 \%)$ were students, $14(23.3 \%)$ housewives and $13(21.7 \%)$ farmers, as shown in Fig. (1). The most common route of exposure was oral route (73.3\%), the most common manner of poisoning was suicidal manner (56.7\%), and the commonest OP compound was malathion (46.7\%), as shown in Fig. (2).

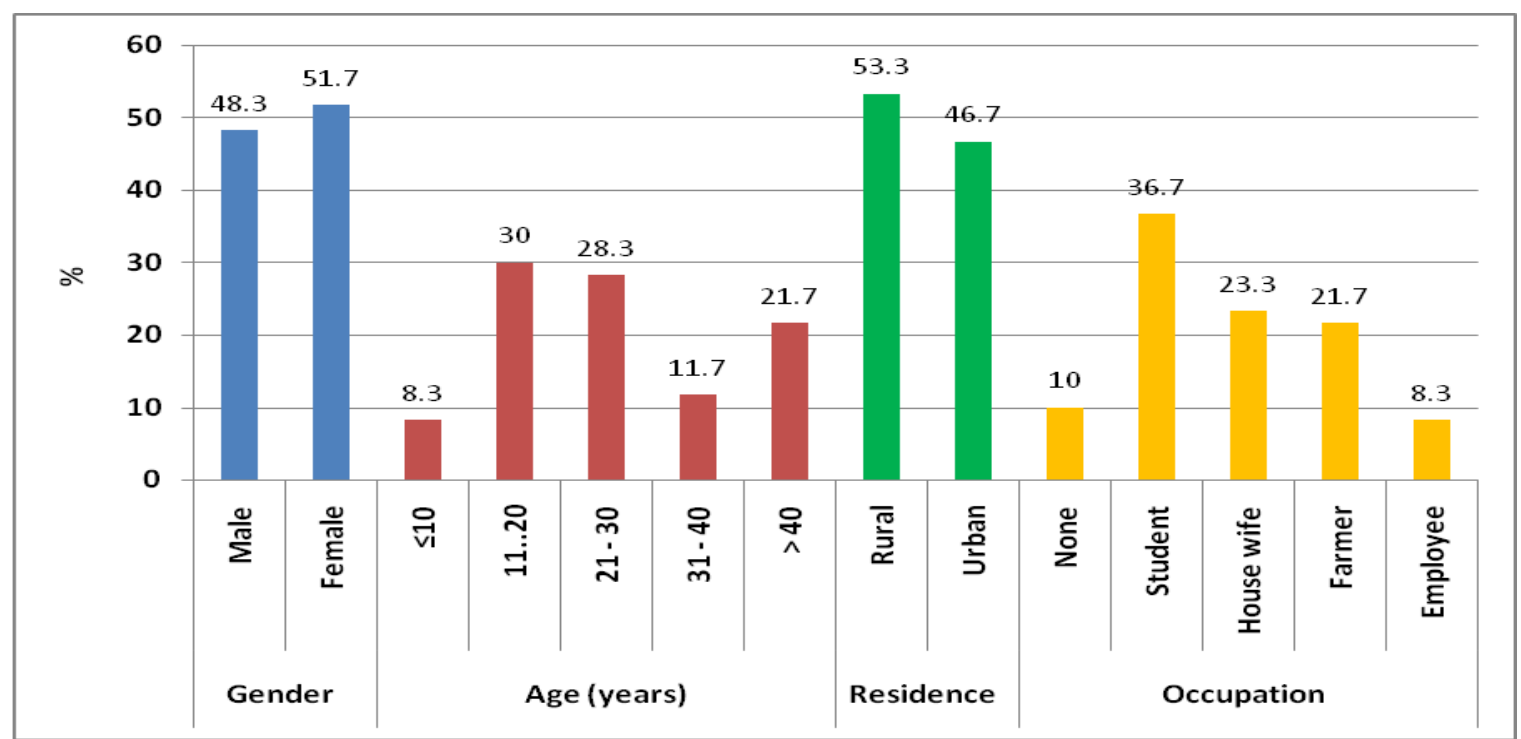

Figure 1 Bar chart illustrating the distribution of the studied patients (No. $=60)$, according to gender, mean age, residence and occupation. 


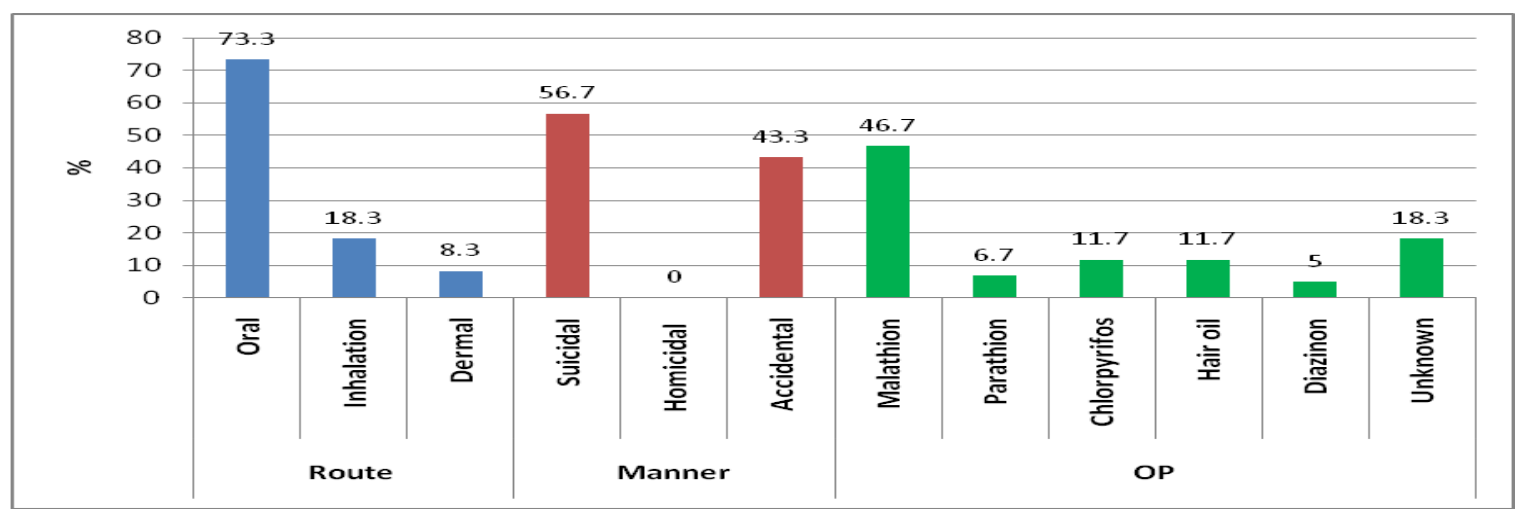

Figure 2 Bar chart showing the distribution of the studied patients (No. $=60)$, according to route, manner of poisoning and type of organophosphorus (OP) compound.

2. CLINICAL RESULTS:

Most of patients manifested with vomiting and abdominal pain $(56=93.3 \%)$, followed by meiosis $(51=85 \%)$, sweating $(43=71.7 \%)$, bradycardia $(42=70 \%)$, salivation $(33=55 \%)$, as shown in Fig. (3).

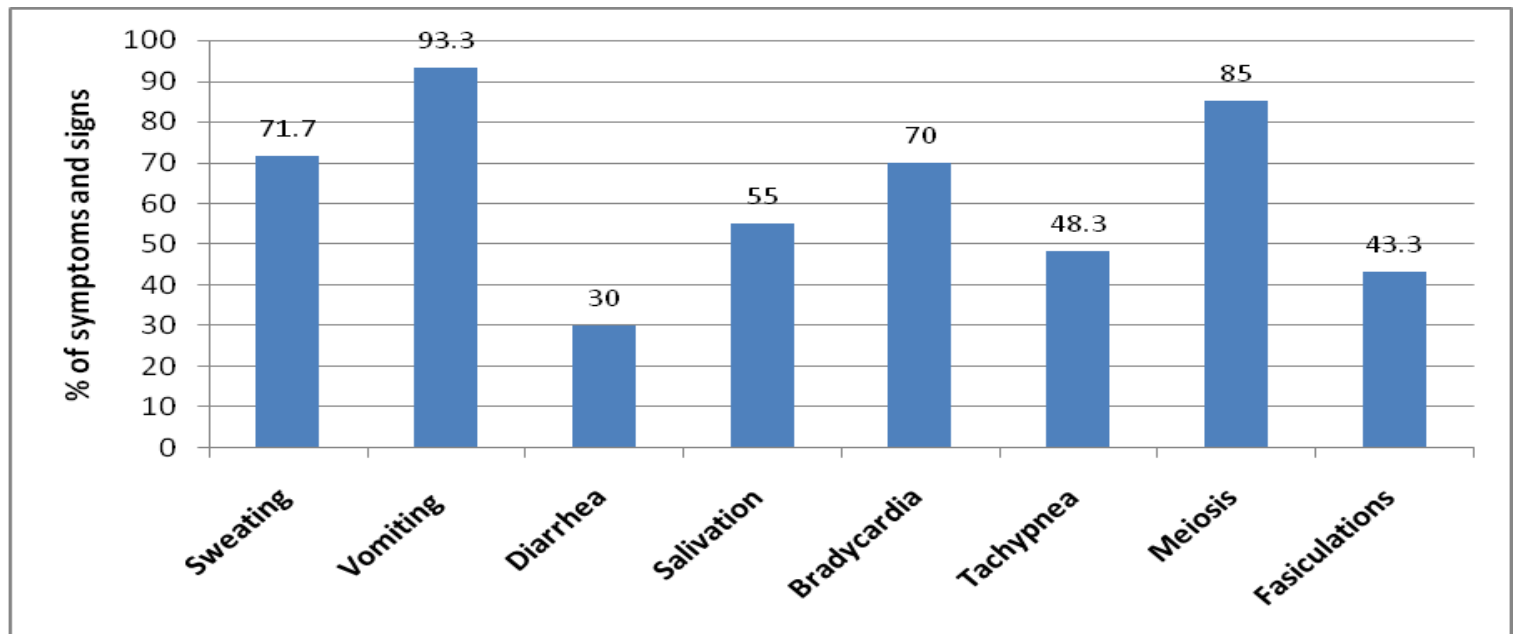

Figure 3 Bar chart highlighting the distribution of the studied patients (No. =60), according to the characteristic symptoms and signs of cholinergic toxidrome.

Out of 60 patients, $31(51.7 \%)$ were mild according to the POP scale, twenty $(33.3 \%)$ were moderate and 9 $(15 \%)$ were severe, as shown in Fig. (4).

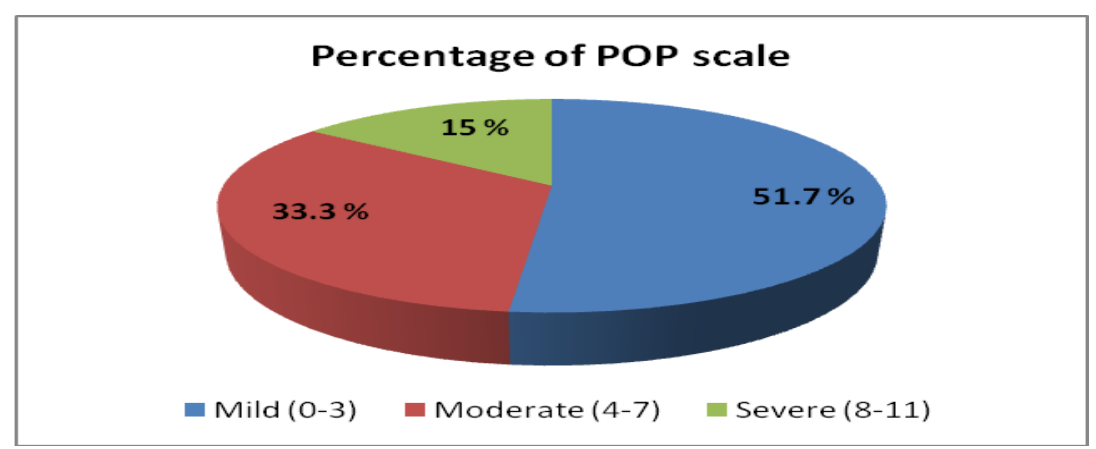

Figure 4 Pie chart showing the distribution of the studied patients (No. =60) according to Peradeniya organophosphorus poisoning (POP) scale.

Glasgow coma scale (GCS), total dose of atropine (mg) and total dose of obidoxime (g) were calculated in relation to the POP scale. The study showed that as the POP scale increases the GCS deceases; whereas the total dose of atropine $(\mathrm{mg})$ and total dose of obidoxime $(\mathrm{g})$ increase. These findings were found to be statistically highly significant $(\mathrm{p}<0.001)$, as shown in Table (2). 
Table 2

Peradeniya Organophosphorus Poisoning (POP) Scale In Relation To: Glasgow Coma Scale (GCS), Ph, Total Dose Of Atropine (Mg), Total Dose Of Obidoxime (G), Serum Butyrylcholinesterase (BChE) (IU/L) And Initial Serum Creatine Phosphokinase (CPK) (IU/L) Of Studied Patients (No =60):

\begin{tabular}{|c|c|c|c|c|c|c|c|c|c|c|c|c|}
\hline \multirow[b]{2}{*}{ POP scale } & \multicolumn{2}{|c|}{ GCS } & \multicolumn{2}{|c|}{ pH } & \multicolumn{2}{|c|}{ Atropine } & \multicolumn{2}{|c|}{ Obidoxime } & \multicolumn{2}{|c|}{ BChE } & \multicolumn{2}{|c|}{ Initial CPK } \\
\hline & Me & \pm & Mea & $\pm \mathrm{SD}$ & Mean & \pm & Mean & \pm & Mean & $\pm \mathrm{SD}$ & Mean & \pm SD \\
\hline $\begin{array}{l}\text { Mild } \\
(0-3) \\
\end{array}$ & 14.3 & 0.60 & 7.41 & 0.031 & 3.54 & 1.52 & 0.30 & 0.15 & $\begin{array}{c}5834 . \\
8\end{array}$ & $\begin{array}{c}2027 . \\
6\end{array}$ & 89.1 & $\begin{array}{c}27.0 \\
9\end{array}$ \\
\hline $\begin{array}{l}\text { Moderate } \\
(4-7)\end{array}$ & $\begin{array}{c}12.2 \\
*\end{array}$ & 1.05 & $\begin{array}{c}7.34 \\
*\end{array}$ & 0.025 & $\begin{array}{c}17.20 \\
*\end{array}$ & 5.91 & $1.13^{*}$ & 0.49 & $\begin{array}{c}2077 . \\
2 *\end{array}$ & 884.9 & $\begin{array}{c}273.0 \\
*\end{array}$ & $\begin{array}{c}96.7 \\
3\end{array}$ \\
\hline $\begin{array}{l}\text { Severe } \\
(8-11)\end{array}$ & $\begin{array}{c}9.4^{*} \\
\dagger \\
\end{array}$ & 0.88 & $\begin{array}{c}7.22 \\
*^{\dagger} \\
\end{array}$ & 0.08 & $\begin{array}{c}37.66 \\
*^{\dagger}\end{array}$ & 7.51 & $\underset{+}{2.25^{*}}$ & 0.52 & $\begin{array}{c}607.4 \\
* \\
\end{array}$ & 278.2 & $\begin{array}{c}688.8 \\
*^{\dagger} \\
\end{array}$ & $\begin{array}{c}86.7 \\
6 \\
\end{array}$ \\
\hline ANOVA(F) & \multicolumn{2}{|c|}{135.3} & \multicolumn{2}{|c|}{78.7} & \multicolumn{2}{|c|}{206.4} & \multicolumn{2}{|c|}{111.4} & \multicolumn{2}{|c|}{57.4} & \multicolumn{2}{|c|}{278.5} \\
\hline$P$ value & \multicolumn{2}{|c|}{$<0.001$} & \multicolumn{2}{|c|}{$<0.001$} & \multicolumn{2}{|c|}{$<0.001$} & \multicolumn{2}{|c|}{$<0.001$} & \multicolumn{2}{|c|}{$<0.001$} & \multicolumn{2}{|c|}{$<0.001$} \\
\hline $\begin{array}{l}\text { Significanc } \\
\text { e }\end{array}$ & \multicolumn{12}{|c|}{ Highly significant } \\
\hline
\end{tabular}

(*) indicates significant difference with the mild POP scale, $(+)$ indicates significant difference with the moderate POP scale

The majority of patients $(42=70 \%)$ had full improvement outcome without complications, 16 (26.7\%) encountered complications like metabolic acidosis, seizures and coma. The mortality rate was 3.3\%, as only two patients died. The mechanisms of death were respiratory failure, acidosis and post-anoxic encephalopathy; their initial CPK levels were high.

\section{BIOCHEMICAL RESULTS:}

The BChE levels (IU/L); initial serum CPK levels (IU/L) and pH values were calculated on admission and in relation to the POP scale. The study showed that as the POP scale increases serum CPK levels increase; meanwhile BChE levels and $\mathrm{pH}$ decease. These findings were statistically highly significant $(\mathrm{p}<0.001)$, as shown in Table (2).

There was a high degree of correlation between the initial serum CPK level and the severity of acute OP poisoning; as illustrated by the positive correlation with (POP scale and total dose of atropine "mg" and obidoxime "g") and the negative correlation with (GCS, serum BChE and $\mathrm{pH}$ ). These correlations were found to be statistically highly significant $(P<0.001)$, as shown in Table $(3)$ and Fig. $(5-10)$.

\section{Table 3}

Spearman's correlation coefficient between the initial serum creatine phosphokinase (CPK) and [Peradeniya organophosphorus poisoning (POP) scale, Glasgow coma scale (GCS), pH, butyrylcholinesterase (BChE) $(\mathrm{IU} / \mathrm{L})$, total dose of atropine $(\mathrm{mg})$ and total dose of obidoxime $(\mathrm{g})]$ :

\begin{tabular}{|c|c|c|c|}
\hline \multirow{2}{*}{ Studied Variables } & \multicolumn{3}{|c|}{ Initial CPK } \\
\cline { 2 - 3 } & Rho & P Value & \multicolumn{1}{|c|}{ Significance } \\
\hline POP Scale & 0.840 & $<0.001$ & \multirow{2}{*}{ Highly Significant } \\
\hline GCS & -0.802 & $<0.001$ & \\
\hline PH & -0.705 & $<0.001$ & \\
\hline BChE & -0.810 & $<0.001$ & $<0.001$ \\
\hline Total Atropine (Mg) & 0.848 & $<0.001$ & \\
\hline
\end{tabular}

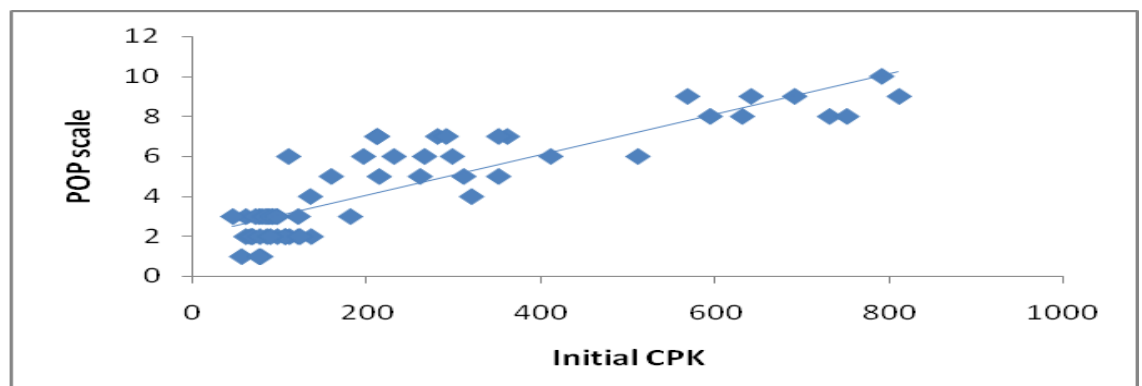

Figure 5 Scatter plot showing the correlation of creatine phosphokinase (CPK) (IU/L) with Peradeniya organophosphorus poisoning (POP) scale $(\mathrm{r}=0.840)$. 


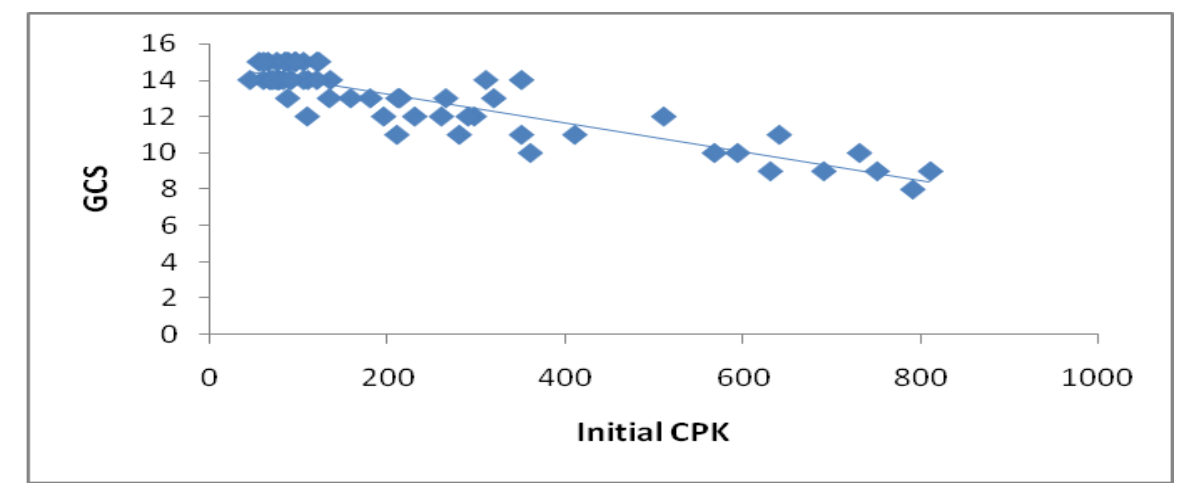

Figure 6 Scatter plot illustrating the correlation of creatine phosphokinase (CPK) (IU/L) with Glasgow coma scale $(\mathrm{GCS})(\mathrm{r}=-0.802)$

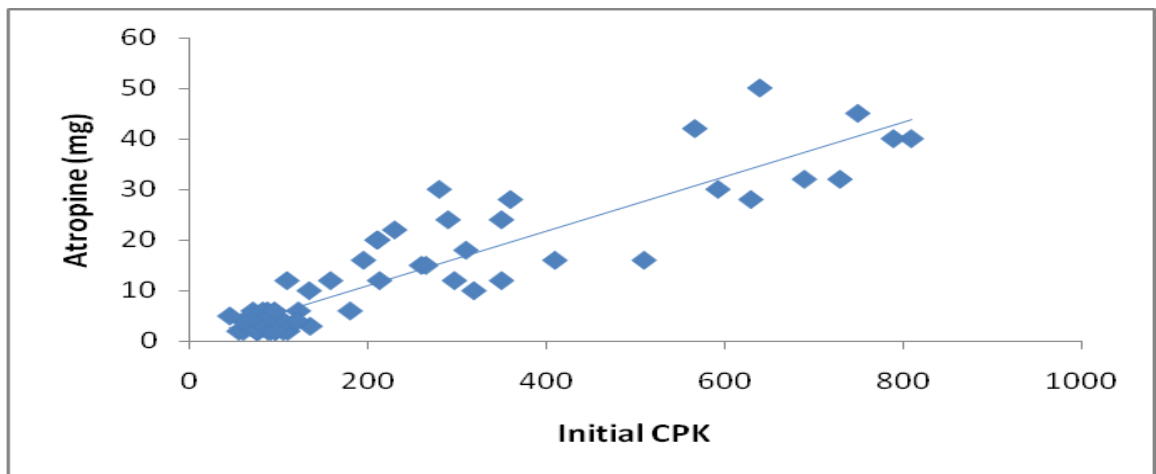

Figure 7 Scatter plot showing the correlation of creatine phosphokinase (CPK) (IU/L) with total dose of atropine $(\mathrm{mg}),(\mathrm{r}=0.848)$

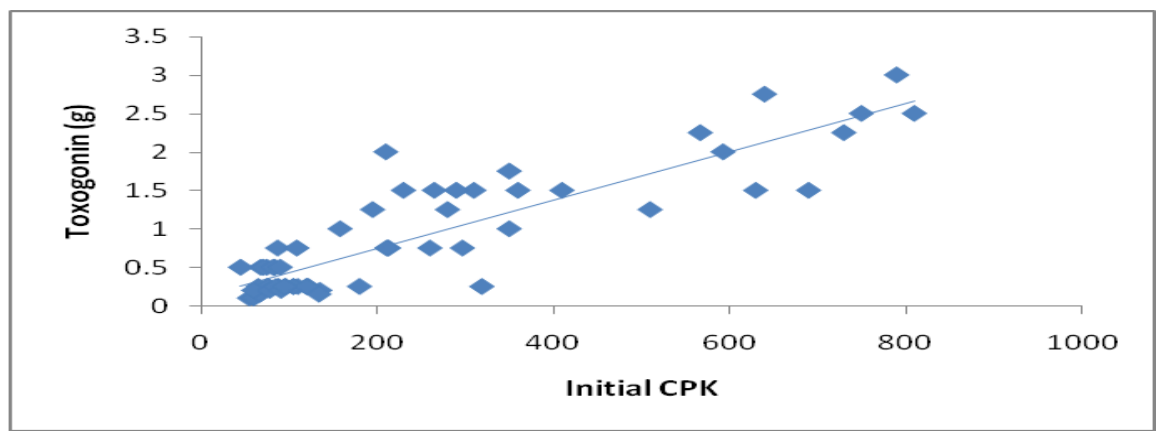

Figure 8 Scatter plot illustrating the correlation of creatine phosphokinase (CPK) (IU/L) with total dose of obidoxime (g) $(\mathrm{r}=0.781)$

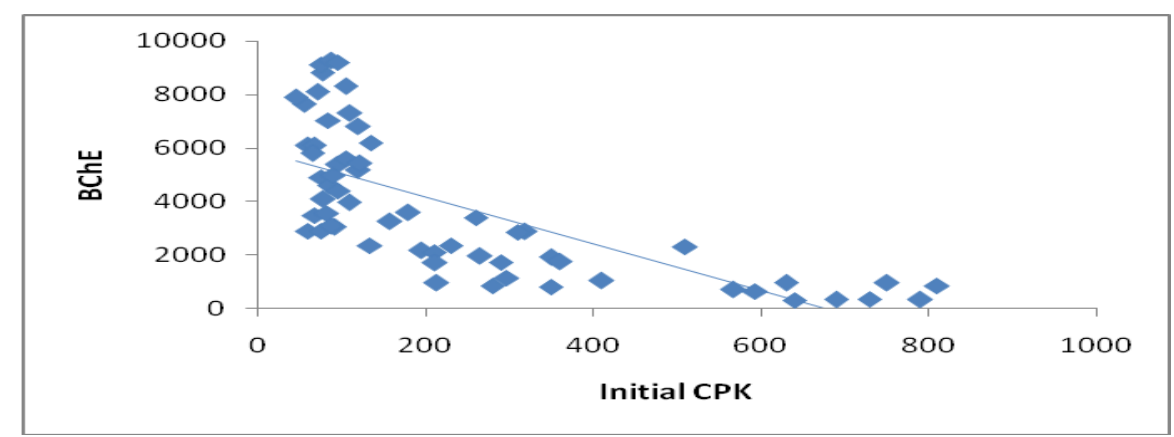

Figure 9 Scatter plot showing correlation of creatine phosphokinase (CPK) (IU/L) with butyrylcholinesterase $(\mathrm{BChE})(\mathrm{r}=-0.810)$ 


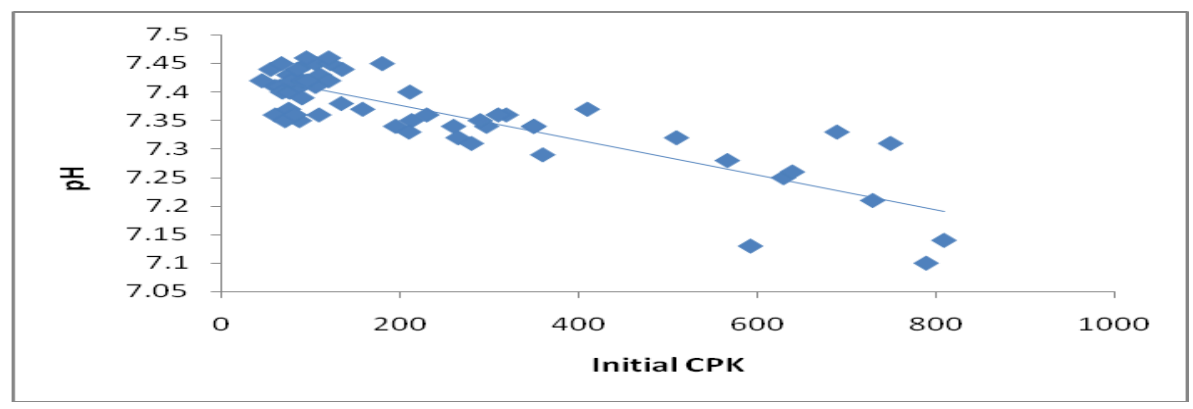

Figure 10 Scatter plot highlighting the correlation of creatine phosphokinase $(\mathrm{CPK})(\mathrm{IU} / \mathrm{L})$ with $\mathrm{pH}(\mathrm{r}=$ $0.705)$

The final serum CPK levels were estimated for 59 patients just before discharging, or after completion of 1 week, whichever was earlier. One patient died on the $2^{\text {nd }}$ day of admission at the intensive care unit during the course of therapy and before completing one week. The final CPK levels were put in comparison with the initial CPK levels, and the study showed that there was a reduction in final CPK levels with treatment in mild and moderate cases, which was statistically highly significant $(\mathrm{p}<0.001)$; meanwhile the changes among the severe cases were non-significant $(p>0.05)$. This was probably due to the widespread of complications that occurred along the course of therapy among patients in the latter group, as shown in Table (4).

The final CPK levels of some patients showed some unexpected results, mainly due to development of complications, as 2 mild cases showed final CPK levels (315 IU/L and $279 \mathrm{IU} / \mathrm{L}$ respectively), while their initial CPK levels were (195 IU/L and $170 \mathrm{IU} / \mathrm{L}$ respectively); the first patient developed an attack of convulsion and the second developed metabolic acidosis during the course of therapy.

Another male patient with moderate poisoning had a final CPK level of $560 \mathrm{IU} / \mathrm{L}$, (initial level was $213 \mathrm{IU} / \mathrm{L}$ ), he developed several attacks of agitations followed by an attack of convulsion combined with altered mental status, and all of these patients were managed successfully with complete recovery.

Table 4

Comparison Of The Initial And Final Serum Creatine Phosphokinase (CPK) Levels (IU/L) Of Studied Patients (No $=60)$

\begin{tabular}{|l|c|c|c|c|c|c|c|}
\hline \multirow{2}{*}{ POP scale } & \multicolumn{2}{|c|}{ Initial CPK } & \multicolumn{2}{c|}{ Final CPK } & \multirow{2}{*}{ Paired "t" } & \multirow{2}{*}{ P value } & \multirow{2}{*}{ Significance } \\
\cline { 2 - 7 } & Mean & \pm SD & Mean & \pm SD & & Highly significant \\
\hline $\begin{array}{l}\text { Mild } \\
(0-3)\end{array}$ & 89.1 & 27.09 & 71.2 & 15.53 & 5.76 & $<0.001$ & Highly significant \\
\hline $\begin{array}{l}\text { Moderate } \\
(4-7)\end{array}$ & 273.0 & 96.73 & 206.9 & 75.21 & 5.42 & $<0.001$ & Non-significant \\
\hline $\begin{array}{l}\text { Severe } \\
(8-11)\end{array}$ & 688.8 & 86.76 & 677.6 & 168.8 & 0.23 & 0.82 & \\
\hline
\end{tabular}

Receiver operator characteristic (ROC) curve was done to assess if the initial serum CPK level can be used as an alternative biomarker for $\mathrm{BChE}$ level in diagnosis of acute OP poisoning. The present study found that the initial serum CPK level is comparable for $\mathrm{BChE}$ level and can be used as an alternative biomarker in diagnosis of acute OP poisoning, provided that exclusion of any other diseases or conditions that may cause rise in CPK levels, these results were statistically significant ( $\mathrm{p}<0.05)$, as illustrated in Table (5) and Fig. (11 \& 12). 
Table 5

Cut Off Values, AUC And CI Of ROC Curve For Comparing Accuracy Of Initial Serum Creatine Phosphokinase (CPK) (IU/L) \& Butyrylcholinesterase (BChE) (IU/L) In Diagnosis Of Acute OP Poisoning:

\begin{tabular}{|c|c|c|c|c|c|}
\hline POP scale & $\begin{array}{c}\text { Variable } \& \\
\text { cut off value }\end{array}$ & $\begin{array}{c}\text { Accuracy } \\
(\%)\end{array}$ & $\begin{array}{c}\mathrm{AUC} \\
\text { (Area Under the } \\
\text { Curve) }\end{array}$ & $\begin{array}{c}95 \% \mathrm{CI} \\
\text { (Confidence } \\
\text { Interval) }\end{array}$ & $P$ value \\
\hline \multirow{2}{*}{$\begin{array}{l}\text { Mild } \\
(0-3)\end{array}$} & Initial CPK $(<146.5)$ & $99 \%$ & 0.99 & $0.97-1.0$ & $<0.001$ \\
\hline & BChE (>2895) & $98.3 \%$ & 0.98 & $0.96-1.0$ & $<0.001$ \\
\hline \multirow{2}{*}{$\begin{array}{l}\text { Moderate } \\
(4-7)\end{array}$} & Initial CPK ( $\geq 146.5)$ & $76.8 \%$ & 0.77 & $0.64-0.9$ & 0.001 \\
\hline & BChE ( $\leq 2895)$ & $77.9 \%$ & 0.78 & $0.66-0.9$ & $<0.001^{*}$ \\
\hline \multirow{2}{*}{$\begin{array}{l}\text { Severe } \\
(8-11)\end{array}$} & Initial CPK ( $\geq 298.5)$ & $98.3 \%$ & 0.98 & $0.95-1.0$ & $<0.001$ \\
\hline & $\mathrm{BChE}(\leq 1100)$ & $96.1 \%$ & 0.96 & $0.91-1.0$ & $<0.001$ \\
\hline
\end{tabular}
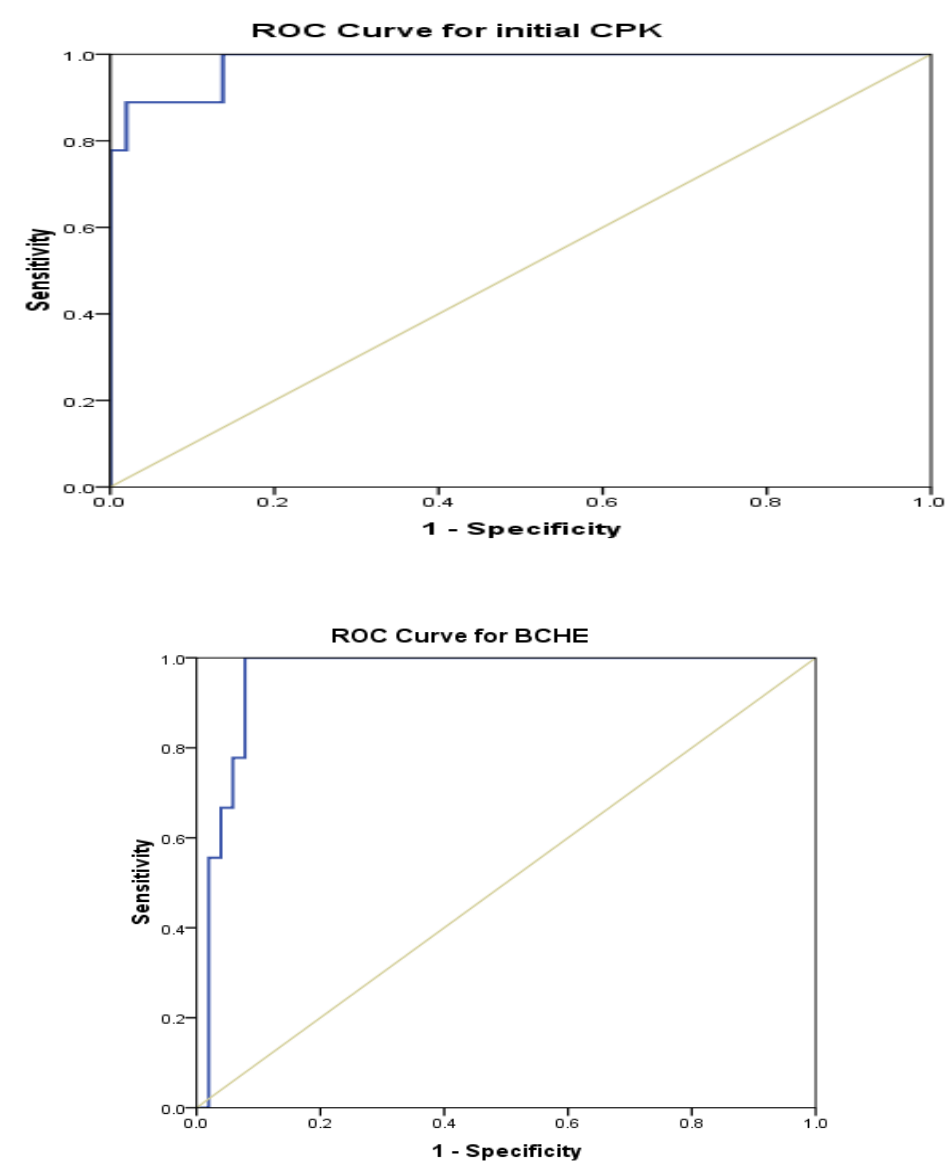

Figures $11 \& 12$ ROC curve for comparing accuracy of initial serum creatine phosphokinase (CPK) (IU/L) \& butyrylcholinesterase (BChE) (IU/L) in diagnosis of severe acute OP poisoning.

\section{Discussion}

Organophosphorus (OP) compounds are among the most commonly used pesticides in agriculture. Because of their wide use and easy accessibility, OP toxicity is important global health problem especially in many developing countries [21, 22]. Every year, hundreds of thousands of deaths occur worldwide due to poisoning with OP compounds [23].

Inhibition of acetylcholinesterase is regarded as the major toxic mechanism of OP, which leads to excess stimulation of muscarinic and nicotinic receptors. The typical clinical picture of cholinergic crisis develops fast, being the basis for clinical diagnosis, which is confirmed by the history and demonstration of 
cholinesterase inhibition [24]. Despite the benefits of acetylcholinesterase monitoring, this test is not available in most parts of the developing world in which there is a high caseload of OP poisoning [25].

The present study showed that out of 60 patients, $48.3 \%$ were males and $51.7 \%$ were females. They were aged from 2 to 53 years, $53.3 \%$ came from rural areas, whereas $46.7 \%$ from urban areas. Regarding occupation, $36.7 \%$ were students, $23.3 \%$ housewives and $21.7 \%$ farmers. The most common route of exposure was oral route $(73.3 \%)$, the most common manner of poisoning was suicidal manner $(56.7 \%)$, and the commonest OP compound was Malathion (46.7\%).

Weissmann-Brenner et al [26] Reported that $66 \%$ of patients with OP poisonings were males and $34 \%$ were females, $39 \%$ were less than 10 years old, $64 \%$ of exposure was accidental, $36 \%$ was suicidal and the most common route of intoxication was oral $(67 \%)$.

The present study illustrated that most of patients manifested with vomiting and abdominal pain $(93.3 \%)$, followed by meiosis $(85 \%)$, sweating $(71.7 \%)$, bradycardia $(70 \%)$ and salivation $(55 \%)$.

Researchers [27] in their study on OP intoxicated patients reported that the most frequent clinical signs were bronchial hypersecretion (52\%), tachycardia (47\%), meiosis (45\%), salivation (41\%), and bradycardia (31\%).

Because an increase of serum CPK concentration always reflects injury to a tissue of high CPK activity, CPK measurements are particularly useful in the diagnosis of many medical conditions like acute myocardial and acute skeletal muscle injuries [28]. Traditional theories relate this CPKemia to agitation, hyperactivity and drugs (i.e. rhabdomyolysis and muscle necrosis) [29].

The present study showed that there was a high degree of correlation between the initial serum CPK levels and the severity of acute OP poisoning; as illustrated by the positive correlation of initial serum CPK level with (POP scale and total dose of atropine in "mg" and obidoxime in "g") and the negative correlation of initial serum CPK with (GCS, BChE levels and $\mathrm{pH})$. These correlations were found to be statistically highly significant $(P<0.001)$.

These results are in agreement with Bhattacharyya et al [14] who confirmed the presence of a high degree of correlation between initial CPK value and POP scale, serum EChE levels, arterial $\mathrm{pH}$ values and total dose of atropine in acute OP poisoning.

Muscle fiber necrosis and consequently raised CPK levels occur in severely acute OP poisoned cases $[30,31]$. So, cheaper, easily quantifiable and more available biochemical markers in relation to OP poisoning like serum CPK can be used in predicting as well as assessing the prognosis of patients with OP poisoning [14]. The severity of OP poisoning in this study ranged from mild, moderate and severe; most of cases were presented with mild OP toxicity. Authors [16] Illustrated that the POP scale can efficiently predict the severity of OP poisoned patients. Meanwhile, authors [32] stated that POP scale uses high respiratory rate and cyanosis, and this approach is likely to be misleading in severe OP poisoning as patients may have either a reduced respiratory rate or tachypnea.

Geller et al [33] highlighted that the total amount of atropine is correlated with severity of OP poisoning, as severely poisoned patients require very large doses (up to $100 \mathrm{mg}$ over a few hours) of atropine determined by chemical titration and control of muscarinic symptoms.

Researchers [27, 34] reported that there was a significant negative linear correlation between the GCS scores and severity of OP intoxication.

Aygun et al [35] illustrated that physicians usually request the BChE activity level to confirm the diagnosis of symptomatic patients with OP poisoning, to classify the severity, and to aid management follow up [36, 37] highlighted the benefits of measuring the BChE activity levels in predicting successful weaning of patient from mechanical ventilation in severe OP poisoning as well as in improving the outcome.

On the other hand, authors [38] stated that BChE measurement on admission has been used to stratify OP poisoning severity. However, it may not be helpful since different OP compounds inhibit BChE to differing degrees compared to their inhibition of the clinically important AChE. BChE activity therefore does not always reflect severity and it must be interpreted carefully.

Acidosis is a major predisposing factor that influences the severity of poisoning and outcome of patients with acute OP poisoning [39]. Liu et al [5] detected that the acid-base interpretation (on arrival) was well correlated with the severity and mortality of acute OP poisoning i.e. the mortality rate was lowest in the group of patients without acidosis and highest in the group with acidosis (metabolic or respiratory).

Acidosis itself can cause modest elevations in CPK levels in blood, which implies that CPK can be falsely high in case of acidosis [40]. However because acidosis is a relatively common complication in acute OP poisoning and can occur due to either hypoventilation (respiratory acidosis) or hypotension (metabolic acidosis), CPK levels were also correlated with the degree of acidosis along with severity of acute OP poisoning [41,42].

Three types of muscle injuries (paralysis) are noticed in OP poisoning. Type I is due to continued depolarization at neuro-muscular junction, type II due to intermediate syndrome and type III due to delayed polyneuropathy[43,44]. 
In the present work, the elevated serum CPK levels were confirmed during the acute stage of toxicity i.e. all cases presented within 6 hours of exposure to OP compounds and before the development of the intermediate syndrome.

This was in agreement with authors [14] who confirmed in their study on OP intoxicated patients that serum CPK level is elevated even in the absence of intermediate syndrome presumably due to muscle fiber necrosis. Intermediate syndrome occurs in between the periods of acute and delayed OP toxicity. The majority of reported cases of intermediate syndrome occur in patients 24-96 hours after acute OP poisoning [7, 45].

Meanwhile authors [46] had linked the raised CPK levels to the rhabdomyolysis in "intermediate syndrome".

But authors [47] highlighted that muscle injury begins during the cholinergic crises and the severity of muscle injury is correlated to the severity of the cholinergic crises. The excess acetylcholine seen in OP poisoning leads to reversible myocyte injury and rise of different muscle enzymes, including CPK.

The present work highlighted the importance of serial measurement of serum CPK levels, as it might be helpful in predicting as well as assessing the prognosis of patients with acute OP poisoning. As follow-up serum CPK levels measured in recovering patients without any complications during the therapy course showed a tendency to decrease. However who were severely poisoned and developed complications during the course of therapy, especially (seizures \& acidosis), continued to remain elevated.

This was in agreement with Sahjian and Frakes [48] who stated that if there is ongoing injury to the muscle due to development of complications, the CPK level continues to be elevated, since half-life of CPK is about 1.5 days; it normalizes within 5-6 days of a single insult to the muscle.

Counselman et al [49] stated that CPK levels peak within 24 to 48 hours of the onset of muscle injury or rhabdomyolysis and then decline at the relatively constant rate of $39 \%$ of the previous day's value.

The present study found that the initial serum CPK level is comparable for BChE level and can be used as an alternative biomarker in diagnosis of acute OP poisoning, provided that exclusion of any other diseases or conditions that may cause rise in CPK levels, these results were statistically significant $(\mathrm{p}<0.05)$.

This was in agreement with Perreault et al [50] who confirmed that when a skeletal muscle is injured, CPK leaks into the blood and urine. Serum CPK level remains the best biomarker for detecting and monitoring skeletal muscle damage and diseases.

Also authors $[14,30]$ confirmed the elevation of serum CPK levels in acute OP poisoning, especially if the patient is severely poisoned, presumably due to muscle fiber necrosis.

However, the main disadvantage of serum CPK as a biomarker for acute OP poisoning, its non-specificity. So, exclusion of other conditions and diseases that may cause its elevation in patients with acute OP poisoning is mandatory. Sniderman [52] stated that numerous factors have influence on CPK activity, so the suitability of $\mathrm{CPK}$ as a biomarker for diagnosis of muscle injury and disease should be viewed with caution. Also, researches $[52,53]$ illustrated that there are multiple causes of elevated CPK, which may affect its reliability as a biomarker.

Also, further studies with greater number of patients and in other locations are required to support the present observations, since the present work was conducted on a relatively small number of patients, and in only one poisoning control unit, with most of cases were presented with mild OP toxicity, and CPK levels are commonly elevated in severely intoxicated patients.

In conclusion, the current study found that:

\section{Conclusion:}

1. Serum CPK level can be used as an alternative biomarker in diagnosis or stratifying severity of acute OP poisoning, as it is cheap, easily available, especially in developing countries where EChE and BChE levels are not widely available in most laboratories.

2. Serial measurements of serum CPK levels in acute OP poisoning can predict the prognosis.

\section{Acknowledgment}

Our deep gratitude and appreciation to our colleges at BPCU, Benha university hospitals, for their great help and valuable constructive cooperation in collection of data of this study.

\section{References}

[1] Terry A V, Functional consequences of repeated organophosphate exposure: Potential non-cholinergic mechanisms. Pharmacol. Therapeut.134: 355-365 (2012).

[2] Chen Y, Organophosphate-induced brain damage: Mechanisms, neuropsychiatric and neurological consequences, and potential therapeutic strategies. Neurotoxicol, 33: 391-400(2012).

[3] Sungur M and Güven M, Intensive care management of organophosphate insecticide poisoning. Critical Care, 5 (4): 212215(2001).

[4] Buyukokuroglu M E, Cemek M, Tosun M et al, Dantrolene may prevent organophosphate-induced oxidative stress and muscle injury. Pesti. Biochem. Physiol., 92:156-163(2008). 
[5] Liu J, Chou C, Liu Y et al, Acid-base interpretation can be the predictor of outcome among patients with acute organophosphate poisoning before hospitalization. Am. J. Emerg. Med., 26: 24-30(2008).

[6] Cemek M, Buyukokuroglu M E, Buyukben A et al, Effects of vitamin E and selenium on tissue bio-element status in organophosphate toxicity of rats. Pesti. Biochem. Physiol., 98: 9-18(2010).

[7] Clark R F, Insecticides: Organic Phosphorus Compounds and Carbamates. In: By: Flomenbaum N E, Goldfrank L R, Hoffman R S et al (eds.), Goldfrank'sToxicologic Emergencies, $8^{\text {th }}$ Edn, McGraw-Hill, New York, chapter (109), (2006) pp: $1497-1513$.

[8] Uzunhisarcikli M and Kalender, Y, Protective effects of vitamins C and E against hepatotoxicity induced by methyl parathion in rats. Ecotoxicol.Environmen.Safety. 74: 2112-2118(2011).

[9] Szatkowska B, Kwiatkowska M, Michałowicz J et al, Impact of chlorfenvinphos, an organophosphate insecticide on human blood mononuclear cells (in vitro). Pesti. Biochem. Physiol., 102: 175-181(2012).

[10] Rubin C, Esteban E, Kieszak S et al, Assessment of human exposure and human health effects after indoor application of methyl parathion in Lorain County, Ohio, 1995-1996. Environment Health Perspectives, 110: 1047- 1051(2002).

[11] Lin T J, Jiang D D, Chan H M et al, Prognostic factors of organophosphate poisoning between the death and survival groups. Kaohsiung J. Med. Sci., 23: 176-182(2007).

[12] Tanen D A, Organophosphorus and Carbamate Insecticides. In: Olson, K.R. (ed.), Poisoning \& Drug Overdose.Lange medical books/McGraw-Hill, ${ }^{\text {th }}$ Edn, New York, Chicago, Toronto, section II, (2007) pp: 291-295.

[13] Bazire A, Gillon E, Lockridge O et al, The kinetic study of the inhibition of human cholinesterases by demeton- S-methyl shows that cholinesterase-based titration methods are not suitable for this organophosphate. Toxicol. In Vitro, 25: 754-759 (2011).

[14] Bhattacharyya K, Phaujdar S, Sarkar R et al, Serum creatine phosphokinase: a probable marker of severity in organophosphorus poisoning. Toxicol.Interna., 18 (2): 117-123(2011).

[15] Agarwal S B, Bhatnagar V K, Agarwal A, et al, Impairment in clinical indices in acute organophosphate insecticide poisoning patients in India. Internat. J. Toxicol., 4: 1-6 (2007).

[16] Senanayake N, De Silva H J and Karalliedde L A, Scale to assess severity in organophosphorus intoxication: POP scale. Hum. Exp. Toxicol., 12: 297-299(1993).

[17] Deutsche G K C, Proposal of Standard Methods for the determination of enzyme catalytic concentrations in serum and plasma at $37^{\circ} \mathrm{C}$, Cholinesterase (AcylcholineAcylhydrolase), Eur. J. Clin. Chem. Clin. Biochem, 30: 163 (1992).

[18] Panteghini M, Bais R and Solinge WW, Enzymes. In: Burtis C A, Ashwood E R and Bruns D E (eds.) Tietz Textbook of clinical chemistry and molecular diagnostics, $4^{\text {th }}$ Edn, Elsevier Saunders, Philadelphia, (2006), chapter (21), pp: 597-643.

[19] Scott M G, LeGrys M T and Klutts J S, Electrolytes and Blood Gases. In: Burtis, C A, Ashwood E R and Bruns D E (eds.), Tietz Textbook of Clinical Chemistry and Molecular Diagnostics, $4^{\text {th }}$ Edn, Elsevier Saunders, Philadelphia, (2006) chapter (27), pp: 9831018 .

[20] Dawson S B and Trapp R, Basic and clinical biostatistics. In: Biostatistics: a foundation for analysis in the health sciences, Lange Medical Book, $2^{\text {nd }}$ (End) prentice - Hall International Inc ,chapter (4), pp: 201-205 (1994).

[21] Karalliedde L, Edwards P and Mars T C, Variables influencing the toxicity of organophosphates in humans. Food Chem. Toxicol., 41: 1-13 (2003).

[22] Akyildiz B N, Kondolot, M , Kurtoglu S et al, Organophosphate intoxication presenting as diabetic keto-acidosis. Ann. Trop. Paediat., 29: 155-158 (2009).

[23] Buckley N A, Karalliedde L, Dawson A et al, Where is the evidence for treatments used in pesticide poisoning? Is clinical toxicology fiddling while the developing world burns? J. Toxicol. Clin.Toxicol, 42 (1): 113-116 (2004).

[24] Thiermann H, Zilker T, Eyer F et al, Monitoring of neuromuscular transmission in organophosphate pesticide-poisoned patients. Toxicol. Letters, 191: 297-304 (2009).

[25] Rajapakse B N, Thiermann H, Eyer P et al, Evaluation of the test-mate ChE (Cholinesterase) field kit in acute organophosphorus poisoning. Ann. Emerg. Med., 58: 559-564 (2011).

[26] Weissmann-Brenner A, Aviv-Vidan A and Hourvitz A, Organophosphate poisoning: A multihospital survey. I.M.A.J., 4: 573-576 (2002).

[27] Tsai J, Sheu C, Cheng M et al, Organophosphate poisoning: 10 years of experience in Southern Taiwan. Kaohsiung J. Med. Sci., 23 (3): 112-119 (2007).

[28] Mongiardo A, Ferraro A, Ceravolo, R et al, Mechanism of troponin and CK-MB release after percutaneous coronary interventions. Ital. Heart J., 3: 270-274 (2002).

[29] Hermesh H, Manor I, Shiloh R et al, Absence of myoglobinuria in acute psychotic patients with marked elevation in serum creatine phosphokinase level. Europ. Neuropsycho -pharmacol., 11: 111-115(2001).

[30] Calore E E, Sesso A, Puga F R, et al, Sarcoplasmic lipase and non-specific esterase inhibition in myofibers of rats intoxicated with the organophosphate isofenphos. Exp. Toxicol. Pathol., 51 :27-33 (1999).

[31] Santos R P, Cavaliere, M J, Puga F R et al, Protective effect of early and late administration of pralidoxime against organophosphate muscle necrosis. Ecotoxicol.Enviroment.Safety. 53: 48-51 (2002).

[32] Eddleston M, Mohamed F, Davies JO, et al, Respiratory failure in acute organophosphorus pesticide self-poisoning. Q.J.M., 99:513-522 (2006).

[33] Geller RJ, Atropine and Glycopyrrolate. In: K R Olson, (ed.), Poisoning \& Drug Overdose, $5^{\text {th }}$ (Edn) Lange medical books/McGraw-Hill, New York, Chicago, Toronto, section II, (2007), pp: 412-413.

[34] Sam K G, Kondabolu K, Pati D and et al, Poisoning severity score, APACHE II and GCS: Effective clinical indices for estimating severity and predicting outcome of acute organophosphorus and carbamate poisoning, J Foren. Legal Med, 16: 239 -247 (2009).

[35] Aygun D, Doganay Z, Altintop L, et al, Serum acetylcholinesterase and prognosis of acute organophosphate poisoning. J. Toxicol. Clin.Toxicol, 40 (7): 903-910 (2002).

[36] Yamashita M. Tanaka J and Ando Y, Human mortality in organophosphate poisonings, Vet. Hum. Toxicol., 39 (2) : 84-85 (1997).

[37] Lee P and Tai DY Clinical features of patients with acute organophosphate poisoning requiring intensive care. Intensive Care Med., 27 (4):694-699 (2001).

[38] Eddleston M., Eyer P, Worek F, and et al, Predicting outcome using butyrylcholinesterase activity in organophosphorus pesticide self-poisoning. Q. J. M., 101(6): 467-474 (2008).

[39] Saadeh AM, Farsakh NA, and Al-Aki MK, Cardiac manifestations of acute carbamate and organophosphate poisoning. Heart, 77: $461-464$ (1997).

[40] Warburton D, Singer D B and Oh W, Effects of acidosis on the activity of creatine phosphokinase and its isoenzymes in the serum of newborn infants. Pediat, $68: 195-197$ (1981).

[41] Erdman A R, Pesticides (Insecticides). In: Dart R C (ed.), Medical Toxicology, $3^{\text {rd }}$ Edn, Lippincott Williams \& Wilkins, Philadelphia, Baltimore, New York, London, (2004), chapter (236), pp: 1475- 1496. 
[42] Karki P, Ansari J A, Bhandary S, et al, Cardiac and electrocardiographical manifestations of acute organophosphate poisoning. Singapore Med. J., 45: 385-389(2004).

[43] Aaron C K, Organophosphates and Carbamates. In: Ford M D, Delaney K A, Ling L J et al. (eds.), Clinical Toxicology, $1^{\text {st }}$ Edn W.B. Saunders Co., Philadelphia, (2001) chapter (102), pp: 983-991.

[44] Yang C and Deng J, Intermediate syndrome following organophosphate insecticide poisoning. J. Chin. Med. Assoc., 70 (11): 467 472 (2007).

[45] Hoffman R S, Nelson L S, Howland M A et al, Insecticides: Organic Phosphorus Compounds and Carbamates. In: Goldfrank'sToxicologic Emergencies, McGraw-Hill Companies, New York, $9^{\text {th }}$ ed., chapter (109), pp: 837-842 (2007).

[46] De Wilde V, Vogelaers D, Colardyn F et al, Postsynaptic neuromuscular dysfunction in organophosphate induced intermediate syndrome. Klin.Wochenschr., $69: 177-83$ (1991).

[47] John M, Oommen A and Zachariah A, Muscle injury in organophosphorous poisoning and its role in the development of intermediate syndrome. Neurotoxicol, 24: 43-53 (2003).

[48] Sahjian M and Frakes M, Crush injuries: Pathophysiology and current treatment. Nurse Pract., 32: 13-18 (2007).

[49] Counselman F L, McLaughlin E W, Kardon E M, et al, Creatine phosphokinase elevation in patients presenting to the emergency department with cocaine-related complaints. Am. J. Emerg. Med., 15 (3): 221-223 (1997).

[50] Perreault S, Birca A, Piper B, et al, Transient creatine phosphokinase elevations in children: A single-center experience. J. Pediat., 159: 682-685 (2011).

[51] Schneider C M, Dennehy C A, Rodearmel S J, et al, Effects of physical activity on creatine phosphokinase and the isoenzyme creatine kinase-MB. Ann. Emerg. med., 25: 520-524 (1995).

[52] Sniderman A D, Is there value in liver function test and creatine phosphokinase monitoring with statin use? Am. J. Cardiol., 94 (s): 30F-34F (2004).

[53] Pore N E 1, Pujari K N and Jadkar S P, Organophosphorus Poisoning, IJBPs, Vol.2: 606 -612(2011). 